\title{
Produtividade e características agronômicas de cultivares de milho safrinha sob plantio direto no Estado de Goiás
}

\author{
Yield and agronomic characteristics of off-season corn crop \\ cultivars under no-tillage system in Goiás State
}

\author{
Milton César Costa Campos ${ }^{[a]}$, Vagner Alves da Silva ${ }^{[b]}$, \\ Ítalo Herbert Lucena Cavalcante ${ }^{[c]}$, Márkila Zunete Beckmann ${ }^{[\mathrm{d}]}$
}

${ }^{[a]}$ Engenheiro agrônomo, Doutor, professor adjunto do Instituto de Educação, Agricultura e Ambiente da Universidade Federal do
Amazonas, câmpus do Vale Médio do Rio Madeira, Humaitá, AM - Brasil, e-mail: mcesarsolos@gmail.com; agromccc@yahoo.com.br
${ }^{[b]}$ Engenheiro agrônomo, Mestre, pesquisador da Agência Goiana de Desenvolvimento Rural e Fundiário (AGENCIARURAL),
Rio Verde, GO - Brasil, e-mail: vasilva@agenciarural.go.gov.br
${ }^{[c]}$ Engenheiroagrônomo, Doutor,professoradjuntoda UniversidadeFederaldoPiauí,Bom Jesus, PI-Brasil, e-mail:italounesp@yahoo.co.uk
${ }^{[d]}$ Engenheira agrônoma, Doutora, professora adjuntada UniversidadeFederaldo Piauí,Bom Jesus, PI-Brasil,e-mail: zunete@fcav.unesp.br

\section{Resumo}

O objetivo deste trabalho foi avaliar as produtividades e as características agronômicas de 49 cultivares de milho safrinha em cinco municípios do Estado de Goiás. O experimento foi instalado em Latossolo Vermelho-Amarelo Distrófico, nas estações experimentais e em propriedades rurais de seis municípios localizados no sudoeste (Rio Verde, Santa Helena, Montividiu e Serranópolis) e norte (Porangatu) de Goiás. O delineamento experimental empregado foi em blocos ao acaso, com três repetições por tratamento. Foram avaliadas alturas das plantas, porcentagem de plantas acamadas e de plantas quebradas, índice de espigas, população, número de espigas, massa de espigas e produtividade. No município de Serranópolis encontrou-se maior altura de plantas, maior massa média de espigas e menor percentagem de plantas quebradas. Apesar de em Serranópolis ter ocorrido altas percentagens de plantas acamadas, isso não influenciou na alta produtividade das cultivares, sendo, portanto, o município mais indicado para as cultivares de milho safrinha testado.

Palavras-chave: Milho safrinha. Zea mays. Caracteres agronômicos.

\section{Abstract}

The objective of this work was to evaluate the yield and agronomic characteristics of 49 off-season corn cultivars in five municipalities of the Goiás State. Experiment was installed in Latosol RedYellow Distrofic, in the experimental stations and rural properties of six municipalities located in the Southwest (Rio Verde, Santa Helena, Montividiu and Serranópolis) and North (Porangatu) of Goiás 
State. The experimental design used was randomized blocks, with three replications per treatment. It was evaluated the plant heights, percentage of felled and broken plants, spikes index, population, number of spikes, mass of spikes and grain yield. In Serranópolis municipality it was found the greater heights of plants, higher average weight of spikes and smaller percentage of broken plants. Despite Serranopolis had presented high percentages of broken plants, this had not influenced the high cultivars productivity and, therefore, it is the more appropriated municipality for the varieties of off-season corn tested.

Keywords: Off-season corn. Zea mays. Agronomic characters.

\section{Introdução}

Historicamente, o cultivo de milho safrinha tem sido associado a uma semeadura de risco, entretanto, com o aumento da demanda mundial e a valorização do milho tem-se cada vez mais aumentado a área de semeadura, assim como a realização de mudanças graduais de investimento por meio do manejo adequado e de híbridos responsivos ao padrão tecnológico (SCHUELTER; BRENNER, 2009). Atualmente, a cultura do milho safrinha no Brasil ocupa uma área de 4.889,8 hectares, com produção de cerca de 18 mil toneladas (CONAB, 2009). Assim, com o crescimento da área plantada e condições climáticas específicas para cada região, a demanda por melhor conhecimento do manejo tecnológico do milho safrinha tem sido cada vez maior, pois o perfil agronômico de um híbrido é definido pelo ambiente em que ele se encontra e por sua referida época de semeadura.

De acordo com Duarte e Paterniani (1998), a adaptação de cultivares a uma determinada região produtora varia com a época de semeadura, e em cultivos extemporâneos as mais bem adaptadas não estão associadas com as da safra de verão. Assim, a avaliação regionalizada de cultivares de milho, no período de safrinha, permite conhecer melhor os ambientes onde cada uma delas se sobressai e comparar suas vantagens e limitações nas diferentes regiões.

Cantarella e Duarte (1997) e Cantarella (1999) concluíram que a resposta da cultura na safrinha varia com o tipo de solo, condições climáticas, manejo e patamares de produtividade. Entre os manejos destaca-se o sistema de plantio direto, que, segundo Feiden (2001), é um sistema ecológico com cobertura morta máxima do solo, objetivando a proteção de sua superfície contra a intensa radiação solar, a redução da queima da matéria orgânica e da amplitude térmica da superfície. Assim, a perda de água por evaporação, o impacto das gotas de chuva sobre a superfície e a velocidade do escorrimento superficial do excesso de água das chuvas são minimizados.

Possamai et al. (2001), avaliando diferentes sistemas de preparo do solo para o cultivo do milho safrinha, verificaram que o sistema de semeadura direta proporciona menor número de dias para florescimento, maiores populações de plantas, maior diâmetro de colmo, maior altura de plantas, maior altura de inserção da primeira espiga, maior número de espigas por hectare, maior índice de espigas de milho e maior produtividade, e que o florescimento antecipado das plantas de milho na semeadura direta resultou das melhores condições climáticas para o estabelecimento e posterior desenvolvimento da cultura.

Em virtude da grande quantidade de cultivares comerciais de milho, da rapidez de sua substituição no mercado e da variabilidade de suas características agronômicas, há uma necessidade crescente de informações para a correta escolha de genótipos mais adequados às condições edafoclimáticas de cada região específica. Além disso, o aumento da área plantada em uma heterogeneidade de condições ambientais e do padrão tecnológico demandado resulta em grande diversidade de ambientes específicos, os quais irão interferir no comportamento das cultivares neles plantadas.

Neste contexto, este trabalho teve como objetivo avaliar o desempenho agronômico de cultivares de milho safrinha, cultivadas em cinco municípios da região Sudoeste e Norte do Estado de Goiás. 


\section{Material e métodos}

O estudo foi realizado no ano agrícola de 2008, com início em 15 de janeiro. Os experimentos foram desenvolvidos em estações experimentais localizadas em propriedades rurais de cinco municípios do Estado de Goiás (Rio Verde, Santa Helena de Goiás, Montividiu e Serranópolis) e Norte (Porangatu).

O solo onde foram conduzidos os experimentos foi classificado como Latossolo VermelhoAmarelo Distrófico típico (EMBRAPA, 2006), com relevo plano (2\% a 3\% de declividade). O clima da região é do tipo Aw, definido como clima tropical úmido com estação chuvosa no verão e seca no inverno, segundo a classificação de Köppen. As temperaturas médias anuais variam entre $20^{\circ} \mathrm{C}$ e $35^{\circ} \mathrm{C}$ e as precipitações oscilam entre $1.500 \mathrm{~mm}$ e $1.800 \mathrm{~mm}$ anuais.

Quarenta e nove cultivares comerciais de milho de diferentes bases genéticas e ciclo foram utilizadas, provenientes de diferentes empresas produtoras de sementes, que são recomendadas para o cultivo de milho safrinha. Os cultivares estudados foram: AG-6690; AG-9010; AS-32; AS-3466; AS-3477; AS-523; C-147; C-333B; C-929; CD-3121; CDX-60; CDX-98D01; CDX-98T03; CDX-98T04; CDX-98T08; CDX-99T05; CO-32; CO-34; CO-9560; D-1000; D-500; D-657; MTC-813N; MTC-828U; MTC-837U; MTC-875U; OC-705; P-3021; P-3027; P-3041; P-30F80; P-30F88; P-30K75; SHS-4040; SHS-4050; SHS5050; SHS-5070; XB-7011; XB-7012; XB-8010; XL-344; Z-8330; Z-8392; Z-8420; Z-8486; Z-84E60; Z-84E80; Z-8501; Z-8550.

O delineamento experimental utilizado foi em blocos ao acaso, dispostos em parcelas subdivididas com três repetições. O fator cultivar foi caracterizado como parcela principal e os municípios como subparcelas.

Para a adubação de semeadura, foi utilizada a formulação 8-20-18 (N, $\mathrm{P}_{2} \mathrm{O}_{5}$ e $\left.\mathrm{K}_{2} \mathrm{O}\right)$ em todos os municípios, aplicando $250 \mathrm{~kg} \cdot \mathrm{ha}^{-1}$; com relação à adubação de cobertura, foi utilizada a fórmula 20-00-20 (N e $\mathrm{K}_{2} \mathrm{O}$ ), aplicando $200 \mathrm{~kg} \cdot \mathrm{ha}^{-1}$, quando as plantas atingiram de 7 a 8 folhas. As fontes de adubo utilizado foram ureia, superfosfato simples e cloreto de potássio.

Foram avaliadas as seguintes variáveis: altura das plantas, altura da inserção da espiga, porcentagem de plantas acamadas, porcentagem de plantas quebradas, índice de espigas (número de espigas por plantas), população, número de espigas por hectare, massa média de espigas e produtividade (calculada com 13\% de base úmida).

Os dados obtidos em cada experimento (locais) foram analisados em conjunto por meio de análise de variância, e as médias comparadas pelo teste de Tukey a 5\% de probabilidade. Após essa etapa, também foram realizadas análises multivariadas (análise de agrupamento), visando a agrupar cultivares com características semelhantes.

\section{Resultados e discussão}

As alturas da planta e da espiga não apresentaram diferenças significativas entre as cultivares, apenas resultaram em diferenças quando foram comparados os dados obtidos nas localidades estudadas (Tabela 1) - o Município de Porangatu foi o que apresentou maior altura de planta em relação aos demais. Esse melhor resultado pode decorrer das condições ambientais do local (temperatura, umidade e radiação), que influenciaram o crescimento das plantas (Tabela 1). Resultados semelhantes foram encontrados por Badillo-Feliciano et al. (1979), em estudo com híbridos e variedades de milho.

Os municípios de Rio Verde, Serranópolis e Montividiu apresentaram resultados semelhantes quanto às alturas de inserção da primeira espiga, e Porangatu apresentou o menor resultado, discordando daqueles encontrados por Mendonça et al. (1999), que variaram entre 1,20 m e 1,45 m de altura. Esses resultados sugerem condições favoráveis em Porangatu, em relação aos demais, uma vez que a maior altura de inserção das espigas na planta a predispõe ao acamamento, concordando com o que concluíram Casagrande e Fornasiere Filho (2002).

Por outro lado, Possamai et al. (2001) afirmam que as perdas e a pureza dos grãos na colheita mecanizada, dentre outros fatores, são diretamente influenciadas pela altura das plantas e, principalmente, pela altura de inserção da espiga. Plantas mais altas e com inserção de espigas também mais altas apresentam 
vantagens na colheita. Resultados diferentes foram encontrados por Santos et al. (2002), que apontam que a estatura da planta aumenta de acordo com a altura de inserção da espiga.

Tabela 1 - Valores médios da altura da inserção da primeira espiga, altura das plantas, plantas acamadas e plantas quebradas do milho safrinha nos diferentes municípios do Estado de Goiás

\begin{tabular}{|c|c|c|c|c|}
\hline Municípios & Altura de planta & Altura de espiga & Plantas acamadas & Plantas quebradas \\
\hline & \multicolumn{2}{|r|}{$\mathrm{m}$} & \multicolumn{2}{|c|}{$\%$} \\
\hline Porangatu & $2,09 \mathrm{a}$ & $0,81 \mathrm{c}$ & $0,67 \mathrm{~b}$ & $0,39 \mathrm{c}$ \\
\hline Serranopolis & $1,99 \mathrm{~b}$ & $1,00 \mathrm{a}$ & $1,78 \mathrm{a}$ & $0,67 \mathrm{bc}$ \\
\hline Santa Helena & $1,89 \mathrm{c}$ & $0,91 \mathrm{~b}$ & $2,45 \mathrm{a}$ & $0,81 \mathrm{ab}$ \\
\hline Rio Verde & $2,00 \mathrm{~b}$ & $1,03 \mathrm{a}$ & $1,50 \mathrm{ab}$ & $1,35 \mathrm{a}$ \\
\hline Montividiu & $1,98 \mathrm{~b}$ & $0,99 \mathrm{a}$ & $2,06 \mathrm{a}$ & $0,73 \mathrm{bc}$ \\
\hline
\end{tabular}

Nota: Para uma mesma característica, as médias seguidas de mesma letra não diferem estatisticamente entre si, pelo teste de Tukey, a $5 \%$ de probabilidade.

Verifica-se, pelos resultados obtidos, que os municípios com maiores porcentagens de plantas acamadas foram os mesmos que apresentaram maiores porcentagens de plantas quebradas (Tabela 1).

Os municípios de Rio Verde, Montividiu e Santa Helena foram os que apresentaram os maiores índices, fato que, para Casagrande e Fornasiere Filho (2002), pode estar ligado à maior altura de inserção da espiga, às alterações da umidade do solo, ao excesso dos ventos e chuvas, assim como a presença de doenças, como antracnose do colmo, que provoca o tombamento e até quebra das plantas. Outro aspecto relevante sobre o acamamento e quebra das plantas, destacado por Dourado Neto et al. (2003), é o adensamento das plantas, isto é, o uso de menor espaçamento entre elas e, consequentemente, maior número de plantas por área (Tabela 1). Quando se comparou as variedades entre si, não houve diferenças significativas em relação ao à porcentual de plantas quebradas; já em relação à percentagem de plantas acamadas, a cultivar P-30F88 foi a que apresentou maiores valores médios (Tabela 1).

No que se refere ao índice de espigas (espigas/plantas), os municípios de Rio Verde, Santa Helena e Montividiu foram aqueles que apresentaram os maiores índices, quando comparados aos demais municípios, com 5\% de probabilidade $(p<0,05)$ (Figura 1). Sangoi e Almeida (1993) e Argenta et al. (2001), testando densidades de plantio e épocas de semeadura, não perceberam aumento do número de espigas em função dessas variáveis. Por outro lado, Forsthofer et al. (2004), estudando épocas de semeaduras e diferentes híbridos, embora não tenha encontrado variação entre os híbridos, observou que a época de semeadura proporcionou aumento na relação espiga/planta, fato que ocorreu em virtude do menor acúmulo de fotoassimilados e maior custo respiratório, na época de elevada temperatura do ar.

Entre as cultivares, aquela que apresentou melhores resultados em todos os municípios, em relação ao índice de espigas, foi a CDX-98T03 (Figura 1). As massas médias das espigas foram superiores nos municípios de Serranópolis, seguido de Santa Helena e Montividiu (Figura 1). Resultados semelhantes foram encontrados por Aguiar e Moura (2003), avaliando parâmetros de duas cultivares de milho, com perspectiva de sua utilização para a agricultura familiar. Segundo Vallejos Mernes (1998), esses resultados podem estar relacionados com o florescimento antecipado das plantas de milho e as melhores condições climáticas para o estabelecimento e posterior desenvolvimento da cultura, proporcionando maior massa das espigas (Figura 1). Todas as cultivares apresentaram os mesmos valores médios de massa.

Quanto às populações de plantas de milho, o município de Porangatu diferiu significativamente dos outros municípios, apresentando maiores populações de plantas e maior número de espigas por hectare em relação aos demais (Figura 2). O aumento deve-se, provavelmente, à maior eficiência da cobertura vegetal, 


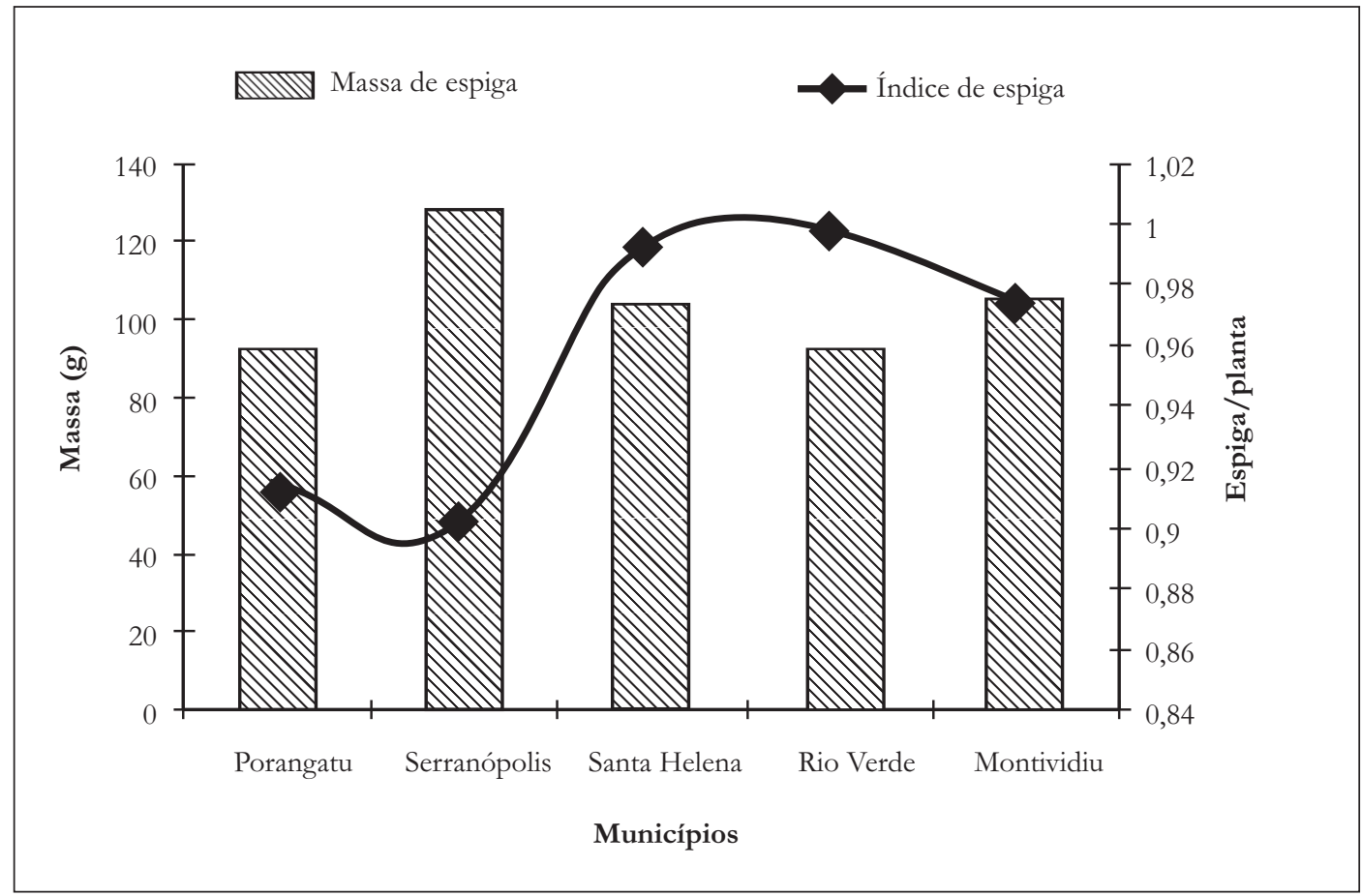

Figura 1 - Índice de espigas e massa média de espigas de milho safrinha nos diferentes municípios do Estado de Goiás

Nota: Para uma mesma característica, as médias seguidas de mesma letra não diferem estatisticamente entre si, pelo teste de Tukey, a $5 \%$ de probabilidade.

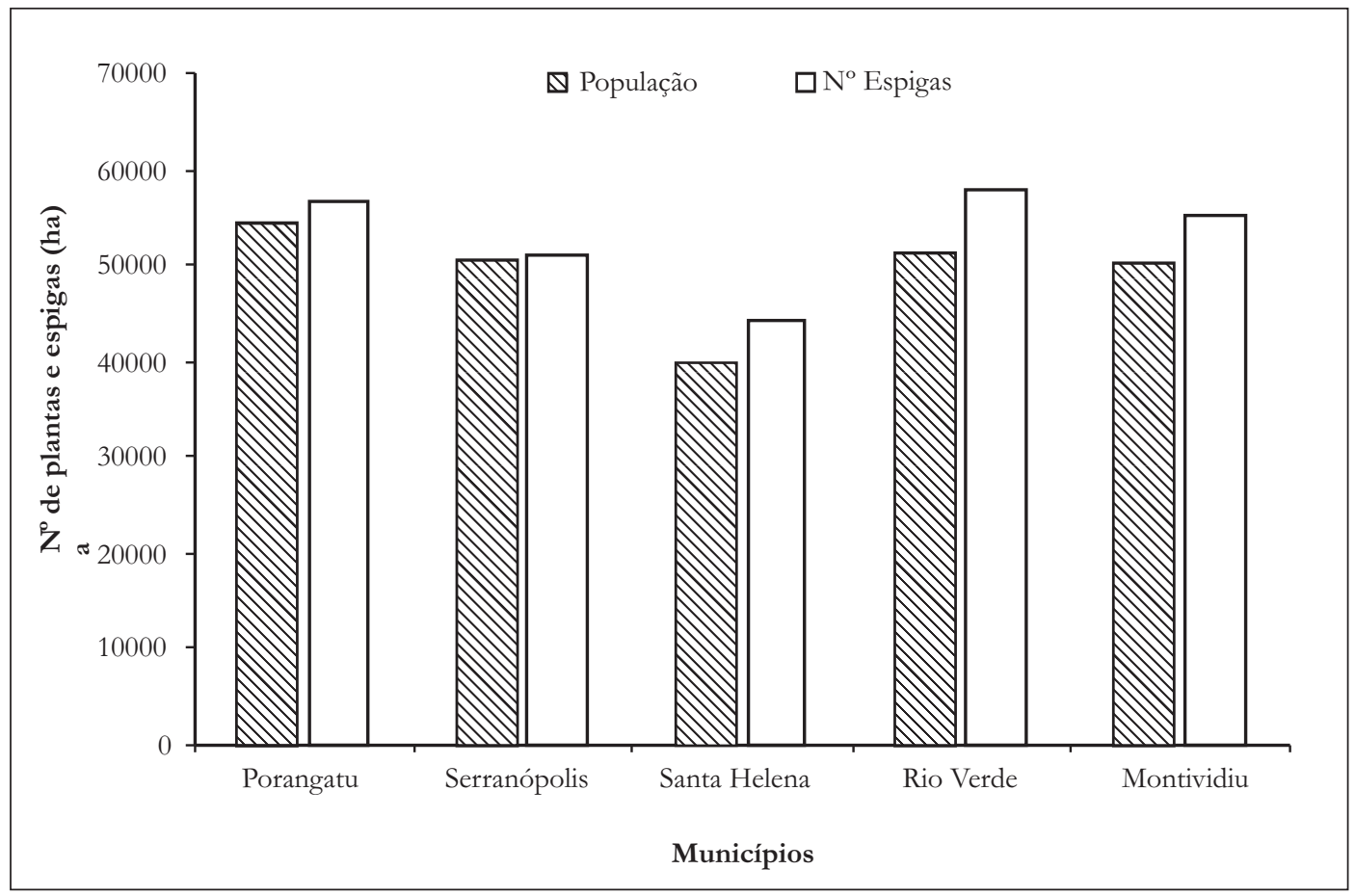

Figura 2 - População de plantas e número de espigas de milho safrinha em cinco municípios do Estado de Goiás

Nota: Para uma mesma característica, as médias seguidas de mesma letra não diferem estatisticamente entre si, pelo teste de Tukey, a 5\% de probabilidade. 
à diminuição das perdas de água e às variações na temperatura do solo (SALTON; MIELNICZUK, 1995), que, por sua vez, propiciaram melhor desenvolvimento da cultura.

Em relação à produção de grãos, houve diferenças significativas entre os municípios, com destaque para Serranópolis, que apresentou resultado mais expressivo, seguido pelo município de Montividiu (Figura 3), provavelmente pelas melhores condições climáticas da região. Em relação às cultivares, a C-333B foi a que alcançou resultado mais elevado, inclusive diferindo estatisticamente das demais. Esses resultados estão de acordo com o que afirmam Possamai et al. (2001), ou seja, o sistema de semeadura direta proporciona maiores populações de plantas e número de espigas por hectare, sendo o milho safrinha mais indicado para o cultivo nesses cinco municípios do Estado de Goiás.

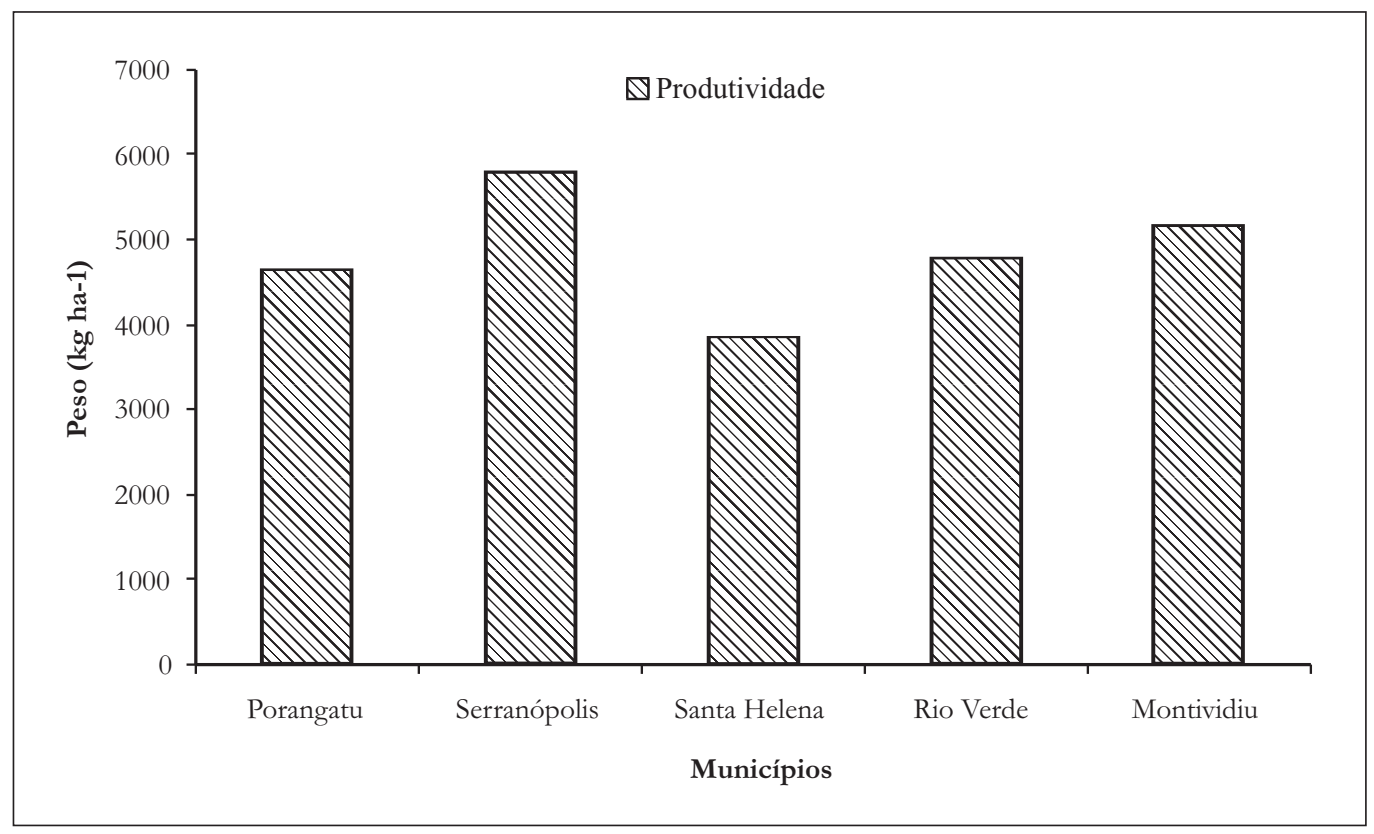

Figura 3 - Produtividades médias de milho safrinha para cinco municípios do Estado de Goiás Notas: Para uma mesma característica, as médias seguidas de mesma letra não diferem estatisticamente entre si, pelo teste de Tukey, a 5\% de probabilidade.

De acordo com Mendonça et al. (1999) e Araújo et al. (2004), que estudaram a produtividade de milho em função da adubação nitrogenada, observaram a relação íntima entre esse elemento e a produtividade dessa cultura; contudo, os autores afirmam que os fatores climáticos têm papel decisivo na produção.

Observa-se na Figura 4 a análise de grupamento das 49 cultivares. Efetuou-se o corte no ponto 6 da Distância Euclidiana e verificou-se a distinção de cinco grupos. O grupo 1 apresentou as seguintes cultivares: D-657, CDX-98T04 e XB-7012; o grupo 2: AS-3477, AS-3466, AG-9010, CO-32, AS-32, C-929, Z-8420, P-3021, CDX-98D01, C-147, MTC-828U, Z-8486, OC-705, MTC813N, SHS-4050, AG-6690, XL-344, Z-8330, CDX-60, Z-84E80, MTC-837U, XB-7011, P-3027, CO-34 e Z-8501; grupo 3: CDX-98T03, CDX-98T08, Z-8392, SHS-5050, AS-523, CO-9560, SHS5070, CDX-99T05, P-3041, CD-3121, MTC-875U, Z-8550, D-1000 e XB-8010; já o grupo 4 foi formado por: SHS-4040 e P-30F88; e finalmente o grupo 5, pelas cultivares: P-30F80, D-500, Z-84E60, P-30K75, e C-333B. 


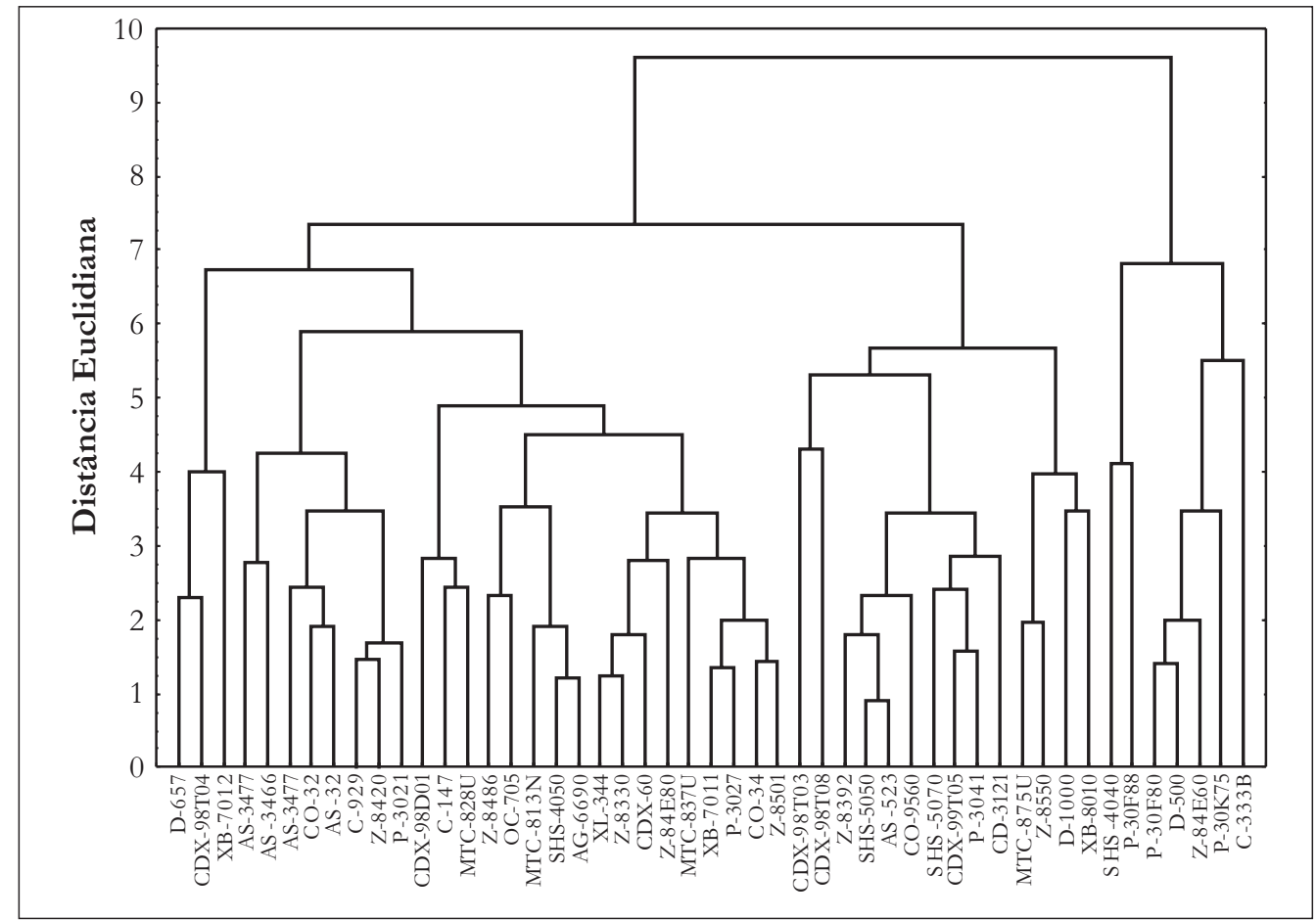

Figura 4 - Dendrograma de agrupamento para 49 cultivares de milho safrinha, avaliadas em cinco municípios no Estado de Goiás

\section{Conclusões}

- No município de Serranópolis encontrou-se a maior altura de plantas, maior massa média de espigas e menor percentagem de plantas quebradas;

- Apesar de em Serranópolis se ter encontrado altas percentagens de plantas acamadas, isso não influenciou a alta produtividade das cultivares, sendo, portanto, o município mais indicado para as cultivares de milho safrinha testado.

\section{Referências}

AGUIAR, A. C. F.; MOURA, E. G. Crescimento e produtividade de duas cultivares de milho de alta qualidade protéica em solo de baixa fertilidade. Bragantia, v. 62, n. 3, p. 429-435, 2003.

ARAÚjO, L. A. et al. Adubação nitrogenada na cultura do milho. Pesquisa Agropecuária Brasileira, v. 39, n. 8, p. 771-777, 2004.

ARGENTA, G. et al. Resposta de híbridos simples de milho à redução do espaçamento entre linhas. Pesquisa Agropecuária Brasileira, v. 36, n. 1, p. 71-78, 2001.

BADILLO-FELICIANO, J. et al. Influence of cultivars, $\mathrm{N}$ levels and time of $\mathrm{N}$ application on plant characters, leaf composition and yield of corn grown on as Oxisol. Journal of Agriculture of the University of Puerto Rico, v. 63, n. 3, p. 273-280, 1979.

CANTARELLA, H. Adubação do milho "safrinha”. In: SEMINÁRIO SOBRE A CULTURA DO MILHO SAFRINHA, 5., 1999, Barretos. Anais... Curso para agricultores. Campinas: Instituto Agronômico, 1999. p. 15-24.

CANTARELLA, H.; DUARTE, A. P. Tabela de recomendação de adubação NPK para milho safrinha no Estado de São Paulo. In: SEMINÁRIO SOBRE A CULTURA DO MILHO SAFRINHA, 4., 1997, Assis. Anais... Campinas: CATI/IAC/IEA, 1997. p. 65-70. 
CASAGRANDE, J. R. R.; FORNASIERI FILHO, D. Adubação nitrogenada na cultura do milho safrinha. Pesquisa Agropecuária Brasileira, v. 37, n. 1, p. 33-40, 2002.

COMPANHIA NACIONAL DE ABASTECIMENTO - CONAB. Acompanhamento de safra brasileira: grãos, intenção de plantio, segundo levantamento, novembro 2009 / Companhia Nacional de Abastecimento. Brasília: CONAB, 2009.

DOURADO NETO, D. et al. Efeito da população de plantas e do espaçamento sobre a produtividade de milho. Revista Brasileira de Milho e Sorgo, v. 2 n. 3, p. 63-77, 2003.

DUARTE, A. P.; PATERniANi, M. E. A. G. Z. (Coord.). Cultivares de milho no Estado de São Paulo: resultados das avaliações regionais IAC/CATI/EMPRESAS - 1997/98. Campinas: Instituto Agronômico, 1998. (Documentos IAC, 62).

EMPRESA BRASILEIRA DE PESQUISA AGROPECUÁRIA - EMBRAPA. Sistema Brasileiro de Classificação de solos. Brasília: EMBRAPA, 2006.

FEIDEN, A. Conceitos e princípios para o manejo ecológico do solo. Seropédica, RJ: Embrapa Agrobiologia, 2001. (Embrapa Agrobiologia. Documentos, 140).

FORSTHOFER, E. L. et al. Desenvolvimento fenológico e agronômico de três híbridos de milho em três épocas de semeadura. Ciência Rural, v. 34, n. 35, p. 1341-1348, 2004.

MAR, G. D. et al. Produção do milho safrinha em função de doses e épocas de aplicação de nitrogênio. Bragantia, v. 2, n. 2, p. 267-274, 2003.

MENDONÇA, F. C. et al. Adubação nitrogenada do milho em um sistema de irrigação por aspersão em linha. Scientia Agricola, v. 56, n. 4, p.1035-1044, 1999.

POSSAMAI, J. M. et al. Sistemas de preparo do solo para o cultivo do milho safrinha. Bragantia, v. 60, n. 2, p. 79-82, 2001.

RESENDE, S. G. et al. Influência do espaçamento entre linhas e densidade de plantio no desempenho de cultivares de milho. Revista Brasileira de Milho e Sorgo, v. 2 n. 3, p. 34-42, 2003.

SALTON, J. C.; MIELNICZUK, J. Relações entre sistemas de preparo, temperatura e umidade de um Podzólico vermelho-escuro de Eldorado de Sul (RS). Revista Brasileira de Ciência do Solo, v. 19, n. 2, p. 313-319, 1995.

SANGOI, L.; ALMEIDA, M. L. Influência do arranjo de plantas e da época de semeadura sobre as características agronômicas de milho e feijoeiro consorciado. Pesquisa Agropecuária Brasileira, v. 28, n. 10, p. 1173-1181, 1993.

SANTOS, P. G. et al. Avaliação do desempenho agronômico de híbridos de milho em Uberlândia, MG. Pesquisa Agropecuária Brasileira, v. 37, n. 5, p. 597-602, 2002.

SCHUELTER, A. R.; BRENNER, D. Precocidade na safrinha: o mito e a realidade. Disponível em: < http:/ / www.pioneersementes.com.br/ArtigosDetalhe.aspx?Id=121>. Acesso em: 30 nov. 2009.

VALLEJOS MERNES, F. J. Influência de sistemas de preparo de solo em algumas propriedades químicas e físicas de um Podzólico Vermelho-Amarelo câmbico, argiloso, e na cultura do trigo (Triticum aestivum L.). 1998. 81 f. Dissertação (Mestrado em Fitotecnia) - Universidade Federal de Viçosa, Viçosa, Minas Gerais.

Recebido: 20/11/2009

Received: 11/20/2009

Aprovado: 22/12/2009

Approved: 12/22/2009 